\title{
Tocar el lenguaje con la mano: experiencias de método
}

\author{
TERESA CARBO \\ CIESAS, MÉXICO D.F.
}

RESUMEN. Este artículo presenta de manera sincética algunos de los postulados, procesos y pasos analíicos seguidos en un estudio extenso de discurso parlamentario, de basse hisrórica y orientación holística, materializado en prácricas lingülsticas y semióticas de análisis verbal, sobre un corpus documentado de desempenos institucionales. La presentación del modelo no es exhausriva pues el texto emana de un evenro oral (conferencia), situación de enunciación que da base a ciertos juegos en las remporalidades de habla y de reflexión y escritura, como planos superpuestos de un ejercicio discursivo que procura dirigirse a sus lectores de manera directa y en modalidad coloquial. En conjunto, el trabajo aspira a ser leído como una intervención (sintética) de (ipo reórico, dedicada al tratamiento de lo metodológico como una instanciación irreductible de tramas conceptuales. Por ello, no se concibe carente de cierros filos polémicos en el espacio de la disciplina.

PALABRAS CLAVE: discurso parlamentario-andisis verbal-juegos temporalidad-habla, reflexión y escritura-intervención teórica-método.

RESUMO. Este arcigo apresenra de maneira sintética alguns dos postulados. processos e passos analíticos seguidos num estudo extenso de discurso parlamentar, de base histórica e orientação holística, macerializado $\mathrm{cm}$ práticas lingufsticas e semióticas de análise verbal, sobre um corpus documentado de desempenhos institucionais. A apresentação do modelo não é exaustiva, pois o texto se produz num evenco oral (conferência), situaçäo de enunciação que permice cerros jogos nas temporalidades de fala, de reflexão e escriura, como planos superposcos de um exercício discursivo que procura dirigir-se aos seus leitores de maneira direta e na modalidade coloquial. Em conjunto, o trabalho pretende ser lido como uma incervençáso(sintérica) de tipo teórico, dedicada ao tratamento do metodológico como uma instanciação irredutível de tramas conceptuais. Por isso, nāo se percebe como carente de certos visos polêmicos no espaço da disciplina.

PALAVRAS CHAVE: discurso parlamenear -análise verbal- jogos temporalidades-fala, reflexao e escritura-intervencao tedrica- metodo. 
ABSTRACT. This article presents in a synthetic manner some of the postulates, processes and analytic steps followed in an extensive study of parliamentary discourse, historically based and hollistically oriented, materialized in linguistic and semiotic practices of verbal analysis of a documented corpus of institutional performances. The presentation of the model is not exhaustive because the text originates in an oral evenc (conference); a siruation of enunciation that gives way to certain games in the cempotal dimensions of speaking and reflecting and writing as overlapping planes of a discoursal exercise that addresses the readers in a direct and colloquial manner. As a whole, it is expected that the paper will be read a (sintheric) theoretical intervencion devored to the treatment of method as an irreducible insranciation of conceptual networks. For this reason, the paper is not conceived as lacking in polemical edges in the space of our discipline.

KEY WORDS: parliamentary discourse -verbal analysis- temporality gamesspeaking, reflecting and writing -theoretical intervention- method.

\section{[Preámbulo]}

Escribi la primera versión de este texto en febrero de 1998, a partir de tres situaciones de conferencia impartidas en Argentina, ('mi?) país, del que salí exiliada en diciembre de $1975 \mathrm{y}$ al que no he vuelto a vivir. En mayo de 1994, Leonor Arfuch me invitó a conversar con los colegas del Seminario de Análisis de Discurso que ella coordina en el Instituto de Investigaciones de la Facultad de Ciencias Sociales de la Universidad de Buenos Aires. En julio de ese mismo año, la Maestría en Sociosemiótica del Centro de Estudios Avanzados de la Universidad Nacional de Córdoba me abrió sus puertas para una presentación informal. La tercera ocasión es el Primer Congreso de Análisis Crítico del Discurso organizado en Buenos Aires por la Sociedad Argentina de Lingüíscica en noviembre de 1996, en donde di también una plática de indole general sobre mi experiencia de investigación.

A pesar de ser un texto introductorio y sencillo, este artículo ha tardado años en alcanzar un destino editorial. Se tejen allí muchos facrores: desde viajes hasta libros universitarios que por razones diversas no logran ser publicados, además del caos regular que invade nuestras vidas, actividades $y$ tareas ( $\sin$ duda, las mías). Ahora (en 2001), que se inaugura la revista de la Asociación Latinoamericana de Estudios del Discurso (ALED), a cuyo contingente de socias fundadoras me honro en pertenecer, es grande mi alegría al poder presentar este material, aunque sea de manera extemporánea. Quisiera pensar que esce texto, que contiene sólo algunas reflexiones sobre el proceso metódico que seguí en la que es hasta ahora mi investigación más ambiciosa (Carbó, 1996), tal vez despierte rodavía algún interés en colegas jóvenes o estudiantes curiosos. He insertado algunas referencias bibliográficas al texco oral, confiando que ésas, al menos, sean de utilidad prácrica. Vaya pues esta publicación con esa sincera y modesta intención. 
Con posterioridad al párrafo anterior, cerca del Día de la Madre (10 de mayo en México, último domingo de octubre en Argentina), y revisando la estructura del texto que ya urgía enviar a Adriana Bolívar, caí en la cuenta de que en varios puntos de su desarrollo, tal vez por razones retóricas de exposición, había yo construido preguntas (encontré 5 preguntas, 1 digresión y algunos paréntesis que envié a notas, pocas). Pensando esas marcas intratextuales útiles como especie de secciones, he añadido títulos [a ciertas partes] y he marcado las preguntas preexistentes de la misma manera (sin corchetes).

Por último, quisiera decir que, aunque el contenido de lo dicho sobre análisis de discurso recoge formulaciones orales $y$ notas de los tres encuentros académicos antes mencionados, he preservado amplias partes de la versión escrita que leí/comenté en Córdoba el 4 de julio de 1994 en la Maestría de Sociosemiótica, ante un escaso aunque selecrísimo publico, en mi ciudad natal y mi universidad de origen. Sirva esto para agradecer la amable asisrencia de María Cristina Pérez Mujica, viuda de Carbó, Matilde Carbó, María Elisa Bettolli, Stella Maris Pascual, Olga Pizarro, Nora Pojomovski y María del Rosario Tissera, quienes me escucharon con amorosa y concentrada atención. Por mi parte, me alegra informar a mis colegas (sobre rodo a quienes estuvieron en Reims), que en aquella afable ocasión cordobesa fui capaz de manejar adecuadamente el tiempo asignado $y$, creo/quiero recordar, satisfice en general las felicity conditions de relevancia y claridad propias del tipo de situación comunicativa "conferencia científica". Así, al localizar espacio-temporalmente el decir (el presence de la enunciación) en ese encuentro, re/construyo una ficción feliz. Los colegas lacinoamericanos, familiarizados con el transterramiento, sabrán admitir una pasajera entrega a la ilusión de que lo irremediable no sucedió (realmente).

\section{[Sobre el estar aqui,]}

El análisis de discurso define a los hablantes no como sujetos en un sentido personal o biográfico sino como ocupantes de lugares (abstractos aunque específicos) en donde se intersectan diferentes líneas de adscripción, identificación, pertenencia o exclusión; el trazo reticular de ciertos puntos en un tiempo y un espacio dados. Esas líneas acotan, delimitan, construyen una posición (segun decía Michel Pecheux, la representación imaginaria de un lugar; 1978) desde la cual una voz (ésta) profiere una palabra (ésta), permeada por la hisroria; modelada de hecho por circunstancias y trazos peculiares. Por otra parte, la letra de un tango famoso afirma que es posible creer que "veince años no es nada". He de asegurarles que esta tarde vivo con particular intensidad y conmoción al mismo tiempo, la verdad y la falsedad de la lírica del anhelo que es ese tango, significativamente titulado, "Volver ..." (Carlos Gardel y Alfredo Le Pera, 1935). 
Hace casi veinte ańos me fui de esta ciudad, habiendo sido cesada administrativamente en abril de 1975 del cargo de Jefa de Trabajos Prácricos en la Cátedra de Metodología de Análisis Literario (con el profesor lber Verdugo), que obruve por concurso, en la Facultad de Filosofía y Humanidades de esta misma Universidad Nacional de Córdobal.

Volver a tener la palabra en el contexto académico universitario cordobés después de todo ese riempo es una experiencia poderosísima que renuncio a intentar explicar. Desde luego me inundan recuerdos personales que no vienen a cuento, y por ello no los trataré, aunque estarán implicados (latiendo aquí) en todo cuanto diga, mientras con singular zozobra no puedo menos que sabet que, como diría el maestro Benveniste (1976), hic et nunc, soy ego en el discurso: quien ocupa en este momento este lugar de habla en particular.

Pero aparte, y puesto que es verdad que en sentido estricto esta voz es la voz de un lugar no biográfico, y que las líneas que llevan, traen, llegan, hasta mi presencia hoy aquí son institucionales y suprapersonales, intentaté hablar desde una posición profesional o científica que es casi por entero figurada. Diré que, para los efectos de esta comunicación, quien habla es una investigadora mexicana que presenta resultados de un estudio reciente ante colegas y especialistas argentinos; también ante algunos familiares cercanos y amigos de buena voluntad, curiosos de las rarezas a las que me dedico desde hace tanto tiempo.

\section{[viniendo de allá.]}

He trabajado por años en el análisis de algunas formas del discurso político de la élite dominante en México, procurando detectar y caracterizar algunas de las operaciones $y$ procesos discursivos puestos en juego para alcanzar lo que se conoció como "el milagro mexicano", experiencia singular en el contexto de los regímenes políticos lacinoamericanos del siglo $\mathrm{xX}$, y que despertó en cantos de nosotros, allá exiliados, una extrañeza tan profunda que henos aquil, investigando2.

Los rasgos básicos del supuesto milagro sociopolítico de México en el ciclo histórico que inició con la Revolución Mexicana de 1910 son conocidos: a lo largo de cierros momentos y etapas en el siglo pasado, hasta 1960 o 65 (sin duda, hasca antes de la matanza de obreros y estudianres en la plaza de Tlatelolco en ocrubre de 1968, poderoso emblerna de cambio de riempos y métodos), el México post-revolucionario habia alcanzado cierto crecimiento econónico y una notable estabilidad política. Entre los grupos dominantes, prevalecía un régimen de distribución relarivamente negociada del poder, el renombre y la riqueza, dentro de un mismo partido político, formalmente electo al gobierno durante décadas. Allí, en la administración más o menos pacífica (o violenca, asimismo, de manera 
ocasional) de acceso a un poder inmenso, también el llamativo logro de una rotación al parecer flexible de los equipos, grupos y alianzas, junto con una imagen internacional aceptable en el continente y en el mundo. Y, sobre todo, estabilidad político-institucional (relativa siempre) en manos de gobiernos civiles, algo cuya resonancia es poderosísima entre nosotros hoy aqui, lo sé.

Ante ese panorama, desde la teoría del discurso me resultó plausible pensar que ese tipo de logros se hubieran beneficiado de la labor prolongada y eficaz de un conjunto de instituciones discursivas que contribuían a la legitimidad de una democracia sui generis, que se mantuvo por lo demás jurídicamente legal a lo largo del ciclo, al menos en términos formales. Es también sabido, y varios grupos de historiadores mexicanos lo formulan desde hace tiempo (Aguilar Camín y Meyer, 1989; Meyer, 1976 y 1977. entre otros), que, además de la retórica postrrevolucionaria, han contribuido cambién a] prolongado funcionamiento de este complejísimo aparato ( $y$ proceso), la corrupción instituida y estructural, el fraude electoral sistemático y la represión precisa y selectiva, dentro de un sistema social, político y económico de desigualdades inmensas, crecientes de manera cada vez más acelerada (Lustig, 1992). Completan este panorama por demás esquemárico un Poder Legislativo claramente subordinado a un poderoso Ejecutivo, una "presidencia imperial" le ha llamado Krauze (1997), ante quien se inclina el Poder Judicial y codo el aparato de impartición de justicia, y un movimienco obrero controlado (con mano dura) por líderes sindicales cooptados hacia la cúspide. En el campo, por su parte, fue reprimida con ferocidad la emergencia de organizaciones independientes, junto a la provecta existencia de una reforma agraria lenta e ineficaz aunque siempre invocada y prometida en el discurso oficial. Empero, tampoco es verdadero que sólo la coerción o la fuerza alcanzaran a explicar la idiosincracia histórico-política del caso mexicano.

Luego entonces, y una vez despertada en mi recorrido personal la pregunta sobre el valor y función de los discursos en esta escena de particular interés, me puse a hacer algunos trabajos sobre discurso presidencial (un lugar central en el régimen), sobre discurso político-panfletario y periodístico (Carbó, 1984; Carbó y otros, 1987), para luego coincidir con los pocos especialiscas de análisis político que objetaban el sobredimensionamiento del papel asignado al Poder Ejecutivo en el logro de esta asombrosa maquinaria de poder (notoriamente, de la Garza, 1972). Intrigada por la configuración hiscórica del régimen político en el que me tocaba vivir, me orienté al discurso parlamentario; específicamente hacia lo que acontece en la Cámara de Diputados. De allí proviene el estudio que hoy les presentaré de manera sumaria.

Añado que, a lo largo del (largo) proyecro, fui motivo de burlas impiadosas por parte de amigos y colegas (con la honrosa excepción de Roberto, 'Canche', Melville, guatemalteco querido y transterrado, también él en Ciesas), 
quienes no lograban ver qué sentido podía tener analizar el discurso parlamentario en un régimen político flagrantemente presidencialista. Además de responder por escrito (Carbó, 1997), tuve ocasión de reir la última pues es claro que la actual prominencia del Poder Legislativo Mexicano en la agitada escena política nacional confirma la crucialidad de esta institución en el orden de los procesos de re/construcción de legitimidad. Antes, como puesta en escena o escenificación ritual (contrafáctica) de la existencia de una efectiva separación de poderes, negada a diario por la preeminencia incuestionable del poder Ejecurivo (Carbó, 1996). Hoy, como territorio necesario para la negociación entre partidos y poderes del Estado, en pos de una efectiva democratización política y tal vez una profunda refundación constitucional.

Lo anterior, por cierto, constituiría un logro cívico que es todavía más que dudoso, a pesar del memorable desalojo del partido gobernante de la Presidencia de la República en las elecciones de julio de 2000, por parte de la oposición (neo)conservadora cuyos inanes primeros desempeños discursivos analicé, el PAN o Partido de Acción Nacional. Hace pocos días, después de Semana Santa (2001), la inaudita aprobación parlamentaria, unánime en el Senado (unânime, sí, como en tiempos de pleno milagro mexicano) y 'al vapor' por mayoría en la misma versión en Diputados, de una supuesta ley indígena, que está más distante de los Acuerdos de San Andrés Larraínzar que la pergeñada por el anterior presidente Ernesto Zedillo Ponce de León, reitera el continuado valor funcional de la institución discursiva legislativa en la oscura administración cupular del poder.

\section{[Sobre lengua e historia,]}

Mi investigación tuvo entonces, desde su inicio, una dimensión descriptiva e interpretativa en el área de lo polírico y lo histórico en sencido amplio. Se propuso contribuir a un mayor conocimiento y a una explicación más fina de cierros procesos institucionales de dominación, cuya materialidad discursiva no había sido analizada por la policología o el derecho. Al mismo tiempo y en vircud de su carácter extenso $y$ longitudinal, que toma como lugar de observación y fuente una misma insticución discursiva a lo largo de varias coyunturas (1920, 1935 y 1948), creo que mi trabajo cumple una función, que me parece valiosa, con respecto a lo que, a partir del maestro Benveniste $(1976,1977)$, interpreto como la responsabilidad descriptiva de la lingüística para con las lenguas de este mundo.

En mi caso, la construcción de un corpus histórico complejo (un complejo longitudinal de corpora, en realidad) permite observar con particular nitidez el peso de lo histórico en la conformación de una institución discursiva, el Poder Legislativo de los Estados Unidos de México, que cumple una función de gran importancia en la reproducción formalmente legítima de ese de- 
terminado sistema político. Por otra parte, el corpus habla también de la delicadeza y 'astucia' con la que el sistema de la lengua, el habla de sujetos sujerados a una estructura suprapersonal, despliega, por ejemplo, en el desempeno parlamentario, posibilidades verbales que, en conjunto, generan efectos discursivos que no son azarosos ni dispersos, sino que contribuyen positivamente a la consolidación ideológica de un cierto régimen de dominación. Todo ello en español mexicano del siglo $x x$. Considero un estudio de discurso de esta naturaleza como un aporte a la descripción de una sincronía dada de lengua, en la evolución de una variante nacional del español americano contemporáneo, testimoniada en una recopilación, intencional y sistemática, de producciones discursivas de índole polémica y pública, en un registro estándar o 'culto'.

Ello nos introduce en la segunda dimensión básica de mi trabajo; primera diría según la cronología personal de mis curiosidades: el hecho de que éste se ocupa de asuntos de lengua, observados desde la lingüística. Concibo el análisis de discurso como un área de la lingüística, entendida ésta en el sentido amplio con el que, entre otros, la ofreciera el maestro Benveniste (1976, 1977). Pero asimismo, quisiera subrayar, como un área de la lingüística descriptiva. Mi práctica de análisis de discurso escucha la lengua con atención primera ( $y$ absorta) a la materialidad verbal de los productos discursivos. Diré más: la intensidad y fineza con la que diversas prácricas, escuelas o enfoques en análisis de discurso trabajan lo que pudiera llamarse 'la forma (de la lengua) del discurso', es un factor decisivo para mí con respecto al incerés que me despiertan.

\section{[y algunos maestros.]}

Por su parte, mi propuesta reórico-metodológica se fundamenta en la unión inseparable de historia y forma linguística en los procesos sociales de construcción de sentido. Pensando y hablando en Argentina tantos años después de tantos hechos tan dolorosos, creo oportuno citar a Eichenbaum (1970), gran maestro en método realista. Dice así:

Para nosotros [los formalistas rusos], reoría e historia se confunden; esta aseveración puede considerarse en su espíritu y en su letra. La historia nos ha enseñado demasiado como para poder creer que pueda evitarse esta unión (p. 54).

Además de suscribir caregóricamente lo anterior, confieso ser cautiva del lenguaje, de la lengua, el hablar, el leer; sin duda, el leer, y en general, lo que es simplemente el decir, con toda su extrañeza y fulgor. Ello empieza aqui, en Córdoba, hace muchos años, en la Escuela de Lecras Modernas de la Faculcad de Filosofía en la Ciudad Universicaria (jinolvidables Pabellones "Espana" 
y "Francia", y "el Anexo"!), pero persevera en el ciclo mexicano de mi vida: el doctorado en lingüística en El Colegio de México, que inicié apenas llegada al D.F., situado aún en la calle Guanajuato 125 de la Colonia Roma Sur, en un edificio que se cayó en el terremoto de 1985 (fenómeno geológico que en México llamamos 'temblor' o 'sismo'; Bradby, 1989).

Volviendo: personal y teóricamente, para mí, el enigma es, ante todo, el lenguaje; el lenguaje entre hombres en sociedad, y sus inagotables maneras de significar. Por lo tanto, el análisis de discurso que practico se pregunta con interés particular acerca de la arquitectura de la forma verbal. Usa lente de aproximación cercana; se pega al material de íntima manera, siguiendo algunos de los múltiples perfiles lingüísticos, 'propiamente lingüísticos', de la superficie textual de los procesos discursivos. Alli se configura y es perceptible la densidad histórica, política, significante, del discurso puesto en acto. Es el dúctil terricorio donde la forma verbal, la forma del decir, despliega una de sus incontables potencialidades expresivas y formativas en una situación social dada. Hallo magnifico este nivel de obsevación de ciertos usos (documentados) de la lengua, fenómenos semióticos con/en los que con/vivimos los hombres, y que constituyen instancias ciertamente no inocentes de prácrica significante, en tanto son historicamente trazadas y ancladas. Pero, asimismo, son usos especificos a la propia lengua, ese sistema semiótico de incomparable eficacia, como dice Jakobson (1976); y también remiten al hablante; los hablantes, todos nosotros, como opción supuesta biográfica que pensamos ser cada uno $y$, en cierto modo, somos. También eso es verdad.

En suma, y cantisimo mejor de lo que yo nunca aspitara a concebirlo, Barthes (1987) formula el espejismo incansable del lenguaje. Quisiera leer en voz alta ante ustedes ahora, el epígrafe que escogi para mi libro, disfrutando de la hermosura de la expresión del maestro, y beneficiándome de la luz oblicua que un epígrafe confiere a la propia y titubeance palabra. Dice así:

... lo imposible no es lo inconcebible: el susurro de la lengua constituye una uropla. ¿Qué clase de utopia? La de una música del sentido ... En su escado utópico la lengua se ensancharía, se desnaturalizaría incluso, hasta formar un inmenso cejido sonoro en cuyo seno el apararo semántico se encontraría irrealizado; el significante fónico, métrico, vocal, se desplegarfa en toda su sunruosidad ... La lengua, susurrante, confiada al significante en un inaudito movimiento, no por ello abandonaría un horizonte de sentido: el sentido, indiviso, impenetrable, innominable, estaría, sin embargo, colocado a lo lejos, como un espejismo ... el punto de fuga del placer (p. 101).

$Y$, además, ya encregada al placer de hablar por voces tan sabias y bellas, quisiera ofrecer también esta otra cita, en la que se dibuja una reflexión sobre método que estimo magistral. Proviene de las ciudades invisibles, sonadas y tenues de Italo Calvino. Por su voz reflexionan de esca suerte el Honorable Kan y Marco Polo, el huésped viajero: 
De ahora en adelante seré yo quien describa las ciudades, había dicho el Kan. Tú en tus viajes verificarás si existen.

Pero las ciudades visitadas por Marco Polo eran siempre distintas de las pensadas por el emperador.

-Y sin embargo, he construido en mi mente un modelo de ciudad, de la cual se pueden deducir todas las ciudades posibles-dijo Kublai-. Aquél encierra codo lo que responde a la norma. Como las ciudades que existen se alejan en diverso grado de la norma, me basta prever las excepciones a la norma y calcular sus combinaciones más probables.

- También yo he pensado en un modelo de ciudad de la cual deduzco todas las otras -respondió Marco-. Es una ciudad hecha solo de excepciones, impedimentos, contradicciones, contrasentidos. Si una ciudad asi es cuanco hay más de improbable, disminuyendo el numero de los elementos fuera de la norma, aumentan las posibilidades de que la ciudad verdaderamente sea. Por lo tanto, basta que yo sustraiga excepciones a mi modelo $y$, en cualquier orden que proceda, llegaré a encontrarme delante de una de las ciudades que, si bien siempre a modo de excepción, existen. Pero no puedo llevar mi operación más alla de cierto limite: obtendría ciudades demasiado verosímiles para ser verdaderas (Calvino,1991, p. 81).

¿QUE ES LO QUE TRATO DE DECIR POR VIRTUD DE ESTAS VOCES AJENAS Y HERMOSAS?

¡Menuda pregunta! En primer lugar, que el análisis de discurso (y también la lingüistica y quizás la ciencia toda) es, entre ocras cosas, la expresión de una manía, de una obsesión, de un empecinamiento en suma, cuyo valor merodológico y teórico no es menor. Al mismo riempo, que todo ello emana del placer, del gozo; del goce, en nuesrro caso, de la lengua; de la convicción que el lenguaje es bello y clocuente, y que induce un estado de entrega al significante que susurra. Se trata, dirla, de una rendición (casi) a la materialidad de la palabra; el ingreso a lo que Barthes llama un "estado de resonancia" (1986).

Aunque por supuesto también intento decir que, en última instancia, el análisis de discurso es una apuesta perdida. El tal momento fundador del decir (en estado de formación) es, por principio, inalcanzable; inexistente desde luego; un punco de fuga, lo sabemos ya. Y el modelo de ciudad, por su parte; esto es, el método, no puede prevalecer por encima de su objeto, borrando de la superficie de ese rostro discursivo los perfiles que lo caracterizan en un tiempo y un lugar determinados.

¿QUE FORMULACIONES CONCEPTUALES Y DECISIONES DE METODO SE DESPRENDEN DE LO ANTERIOR?

Unas cuantas, de importancia fundamental para el tipo de análisis de discurso que intento practicar. Sintetizaré toscamente, me temo, para abreviar el relato. En cuanto método, quisiera destacar ante todo el recurso a la lectura; si, a la lectura como herramienta metodológica específica en el marco de una linguística que no reniega de la propia competencia de hablance del analista. sin que ello implique para nada la conversión de éste en un sujeto todopode- 
roso en el centro del sentido y el saber (Carbó, 1996). Por lo demás, cuando hablo de lectura, hablo verídicamente de leer, de leer y releer el material, y de volverlo a leer $y$ releer hasta que el oido del analisra se afina, se educa y sintoniza, diría, con aquello que, desde el discurso, comienza a hablarle. En análisis de discurso, ejerzo (y recomiendo) la práctica de una serie de movimientos de lectura y relectura. Sólo de ese modo, lento y paciente, es posible alcanzar la inmersión en una escucha de estilo flotante, una lectura/escuchaImirada (fija, o casi) que, deliberadamente distraída, se va dejando asir por ciertos perfiles de lo dicho (Carbó, 2001).

Todo esto se relaciona a su vez con el (otrora) dilema en el área disciplinaria, con respecto a normalización o literalidad de los materiales que integran el corpus. Ejerzo (y recomiendo) la preservación de una completa integridad textual en los productos discursivos que se estudian. Estoy convencida de que la literalidad de lo dicho es un dato fundamental en el análisis ( $\mathrm{i}$ y en la vida! véase Carbó, 1989, citada en Piccini, 1989). Al respecto, me interesa subrayar que, en los tiempos de la normalización instituida por Michel Pecheux y la revista Langages, sólo Eliseo Verón (1971) señaló el valor crucial de la preservación de la literalidad. Lo hizo en un trabajo clásico, elaborado en 1967 para un seminario del Instituto "Torcuato di Tella" en Buenos Aires, con el interés anadido de vincular el asunto de la literalidad con un 'no saber' del analista respecto a la índole y lugar de ocurrencia de los fenómenos cuyo estudio emprendía; discursivos, diríamos hoy; ideológicos y semáncicos se designaban entonces. En esos mismos años, Denise Maldidier (1971) publicó en París un trabajo sobre la guerra de Argelia en el que adopraba una solución muy inteligente ( $y$ elegante! se diría en ciettos modelos científicos) con respecto al curso del tiempo en el objeto y la necesaria regularidad en el análisis de la mareria cexcual. Lo hizo por medio del establecimiento de frases (documentadas) en cada ciclo o sincronía como 'canon' o epitorne del asunto (en movimiento), analizando el grueso de la producción verbal habida en cada sincronía en relación con esas frases, asumidas emblemácicas; un trabajo breve, precioso, donde la discusión más apasionante sobre decisiones de mécodo aparece, láscima, en notas.

Mi opción por la literalidad, y ortos asuntos teórico-metodológicos que no podré desarrollar aquí, me conducen a un acceso analítico a la materialización verbal de los fenómenos discursivos que cranscurre predominancemente en el nivel de la estructura sintácrica de dichos procesos y productos, $y$ que es de índole manual. Manual, e incluso manteniéndose el analista siempre próximo a su objeto (¿fetiche?). En la senda del maestro Jakobson (1981:87-97), he podido comprobar que lo sintácrico es un espacio privilegiado para la detección de los principios constructivos con los cuales el discurso, histórico por definición, adquiere su peculiar trazo y espesor significante en cuanto materia verbal (Carbó 1984, 1996).

En suma, el método, entendido como conjunto ordenado de decisiones de conversión del material en daco, esto es, en material parlante, aspira a 
construir los cimientos y las fronteras de una escucha, de una lectura, que no acrúe sobre los materiales como el modelo maquinaria del Honorable Kan, pero que tampoco sea una lecrura delirante (la psicosis sería la creencia en la significatividad profunda e intencional de todo cuanto nos rodea). La práctica metodológica compleja que intento esbozar, aspira a ser una lectura que no sólo sea mi lectura pero tampoco una lecrura o escucha cualesquiera. Lo diré otra vez: es el conocimiento histórico, la historia en suma, quien educa, informa, afina o sintoniza ese oído (¿lingüístico? ¿sintáctico? ciertamente, estructural y pautado) que escucha al discurso discurrir.

\section{¿QUE LOGROS DESCRIPTIVOS SE ALCANZARON DE ESTA MANERA?}

En primer lugar, se pudo comprobar la verosimilitud de la reoría del discurso con respecto a la capacidad constitutiva de lo discursivo en lo social y político. Es decir: fue posible derectar la contribución primordial del Poder Legislativo Mexicano a la legitimación y estabilidad del régimen político en su conjunto. Ello sucede por medio de operaciones que el análisis logró establecer con cierta nitidez: la Cámara de Diputados funciona como una caja de resonancias para la presentación y garantizada aprobación de las propuestas de un Poder Ejecutivo prácticamente omnímodo. En esa condición, los sujetos institucionales que participan en la escena discursiva (esto es, los diputados concebidos como hablantes) ejercen labores verbales que son predominantemente de glosa, paráfrasis y expansión argumental sobre los textos escritos (o Iniciativas) que emanan del Presidente de la República, un hablante de hecho inobjetable.

Por el mismo principio, en el momento del discurso oral o debate, fue posible observar que la ecapa interaccional del fenómeno parlamentario consistía en la realización de una compleja escenificación ritual (me siento en la obligacion de subrayar que cambién apegada a derecho) de aquello de lo cual el régimen precisamente carece de facto. El desempeńo discursivo del Poder Legislativo Mexicano actúa, pone en acto, la existencia de una efectiva separación de poderes, cual en un sistema de democracia política representativa. Al mismo ciempo, permite cambién aflorar y procesar dentro de la Cámara de Dipurados (sólo hasta cierto punto, desde luego), las reales diferencias de incereses, las discrepancias argumentales e ideológicas y las confrontaciones persistentes, que delatarían la presencia de profundas grietas y fisuras en el sector de la élite dominante allí admirido. Por último, y puesro que mi escudio, como dije, cubre un ciclo cronológico bastante excenso, fue también posible observar el laborioso proceso histórico de disciplinamiento del propio Poder Legislativo como el tipo de institución sui generis arriba esbozada, dentro del repertorio de recursos, con frecuencia feroces, con los que los detentatarios de la revolución triunfante ejercieron tareas de (auto)control.

Esta élice poscrevolucionaria puede ser caracterizada como la expresión de una alianza o pacto corporativo interclasista que, por definición y práctica, ha 
estado plagada, a lo largo del ciclo que estudié, de tenaces conflictos y luchas de poder. La callada y más o menos armoniosa escenificación parlamentaria no logró nunca del todo soterrar estas heridas activas (contradicciones, enfrentamientos) con respecto al rumbo del proceso de dominación que compartieron en un ciclo. Todo ello, además, hubo de ser logrado ( $y$ en ese sentido, el éxito es notable) sin arentar contra la auroridad o el prestigio del Poder Ejecutivo en rurno; aunque ha habido, por supuesto, diferencias perceptibles entre ciclos.

En cierto momento del tramo 1920-1950, en el ciclo de la postguerra, las crecientes necesidades de legitimación política del régimen dictaron la conveniencia de incluir en la Cámara de Diputados algunos representanres, así fueran cuasi simbólicos, de los escasos y pequeńos partidos de oposición. Estos diputados, incorporados al Congreso por medio de una reforma a la ley electoral en 1946, cumplieron importantes funciones en el ciclo de mayor esrabilidad del régimen mexicano. Además de contribuir a la plausibilidad de la puesta en escena de una democracia formal, inyectaron al momento de debate una cuota de vivacidad que emanaba de las reales inconformidades de una verídica oposición política, muy pequeña al principio (jy proveniente de la derecha católica!), contra el partido hegemónico, ante el cual ésta fue de todos modos siempre conminada a actuar como una oposición leal y "razonable" (Meyer, 1977).

La crisis, que hoy está lejos de resuelta, comenzó a ser visible dentro del ciclo cubierto por la observación. Se manifestô, por cierro, en dimensiones específicas de los fenómenos discursivos que habían sido detectados como característicos del objeco analizado. Procuraré explicarme puesto que ello es interesante con respecto a las apuestas teóricas y metodológicas que yo me haba formulado. Establecido que fue mi objeto de estudio, la lectura y descripción subsiguiente detectaron en él la presencia de ciertos rasgos de comportamiento interaccional; por ejemplo, usos claramente polémicos de ciertas posibilidades pragmáticas implicadas en la situación de debate, trátese de mociones de orden o de pedidos de la palabra "para hechos", juicios de im/pertinencia en el desempeño inceraccional ("apartarse del asunto a debate", entre otros), amén de interrupciones, aplausos, chiflidos y ruidos diversos.

En 1988, lo que sucedió en México durante el informe del Presidente de la República al Congreso de la Unión, puede sinterizarse en el fenómeno, muy frecuente duranre el período que estudié (aunque, desde luego, entre pares y no hacia el Presidente), de "Serie de interrupciones al hablante en turno" (Carbó, 1996, p. 181, 184-5). El entonces senador Porfirio Muñoz Ledo lo que hizo fue una simple (e?) transgresión estatutaria: interrumpió en varias ocasiones, con clara orientación disrupriva, al presidente en ejercicio $\mathrm{Mi}$ guel de la Madrid Hurtado mientras éste rendía ante el Congreso su último informe anual de labores el $1^{\circ}$ de septiembre, en solemne ceremonia. Lo que alli se rompió, es claro, fue mucho más que un callado acuerdo interaccional 
y político. Se trataba del quiebre, primero y final se diría, de un ritual político de alto valor simbólico, que expresaba una alianza en la cúspide. Desde entonces hacia acá, la crisis del modelo no ha hecho sino agravarse. Será preciso un nuevo pacto constituyente en México para que ciertos espacios institucionales, el Congreso por ejemplo, recupere el ejercicio pleno de sus facultades, al tiempo que se reconfiguran sus potencialidades discursivas.

¿POR MEDIO DE QUE PROCESOS Y RECURSOS DE MÉTODO SE LOGRÓ ESTA DESCRIPCION INTERPRETATIVA?

Algunos, en términos generales, han sido ya mencionados. Otros lo serán brevemente. En la línea del grupo francés de analisis de discurso, mi trabajo analiza un corpus histórico amplio, construido a partir de un acervo de archivo significativamente más extenso. El ingreso al archivo fue de orden léxico; no en el sentido de búsqueda de recurrencias, sino léxico en una dimensión temática o tópica. Se extrajeron del archivo todos aquellos trámites legislativos, entre 1920 y 1970, cuya designación en el registro oficial de la institución discursiva estudiada (el Diario de los Debates de la Cámara de Diputados del Poder Legislativo Mexicano) incluyera uno u otro o los dos siguientes elementos léxicos o términos: "indi/o/s, indi/gena/s, étnic/o/a/s" y "educación" (con variantes y derivaciones). La fuente, así interrogada, de manera manual sistemática, ofreció un volumen amplísimo de materiales que constituyeron el acervo del estudio y fueron posteriormente el origen de su corpus u objero de análisis. El acervo registra 165 entradas a lo largo de 55 años y el corpus se compone de siete entradas en tres grupos a lo largo de 28 años (Carbó, 1996); la capacidad de generalización del estudio con respecto a los rasgos básicos de la escena discursiva observada se extiende hasta después de 1970.

La construcción o consritución (que no "recopilación") del corpus, como siguiente momento metódico, implica el recurso a criterios de otro orden. La selección de los mareriales en el nivel mismo del acervo obedece a principios de selección y combinación que son en realidad argumentales: buscamos (todos nosotros), en cada caso, de/mostrar ciertas cosas con el análisis del corpus como evidencia empírica. Ciertamente, mi acceso léxico-temático al archivo implicaba ya, desde un punto de vista teórico y metodológico, la concepción de un cierco asunto histórico-político y la presencia de hipótesis (al menos exploratorias) con respecto a su perfil específico. Ciertamente, también, mi escrucinio de documentos y trámites en el archivo partía del (previo) saber que el tópico de la educación indígena en el discurso parlamentario mexicano podía constituir una instancia adecuada (que resultó óptima, por cierto) para observar el desempeño del régimen postrrevolucionario en sus procesos discursivos de diseño de acción gubernamencal. Ello, en tanto el asunto de los grupos étnicos y su parricipación en los beneficios posteriores a la lucha armada exhibe con particular nitidez las dificultades que la élite gobernante hubo de afrontar con respecro a las concradicciones que emergían entre un ré- 
gimen discursivo que se decia heredero de un movimiento insurgente de origen campesino y orientación democrática, y los hechos de un régimen político y económico crecientemente desigual en la distribución de casi todos los bienes deseables de este mundo.

\section{[Sobre el corpus]}

De igual modo, a lo largo del proceso de conversión del material en dato, los criterios de construcción del corpus combinaron varias dimensiones. Por un lado un cierto saber histórico e institucional (no desdeñable) con respecro a la periodización 'macro' del prolongado ciclo que se observaba (el de la postrrevolución triunfante en el siglo $\mathrm{XX}$ ). Es claro también que la colocación de esta mirada de pertinencia histórica, si así puede llamársele, se ajustaba a las preguntas que orientaban el propósito de la demostración. En este caso: la obtención de evidencia discursiva sobre el proceso de construcción del más carde cuasi 'naturalizado' presidencialismo mexicano, desde un lugar diferente al propio Poder Ejecutivo, y a propósito de un tema (el indigenismo) de clara importancia en el ejercicio retórico del régimen político. Por otra parte, la construcción del corpus escrutó también si las coyunturas institucionales preseleccionadas (la creación parlamentaria de algunas inscituciones indigenistas de alcance nacional y propósito asistencial específico) ostentaban en su realización verbal parecidas o diferentes configuraciones discursivas, o morfologfas específicas, podría también decirse.

Todo ello con el graco resulcado de que la teoría con respecro a la imbricación estrechísima (co-constitución es sin duda una designación más apropiada) entre historia y materialización significante de los procesos discursivos se confirmaba de una manera plena y hasca casi hermosa: no sólo era posible encontrar que la creación de instituciones indigenistas ocurría en determinados momentos históricos de particular 'densidad' (institucional, polírica, ideológica, cultural, económica), sino que cambién y por el mismo principio ( $y$ puesto que se trataba de coyunturas muy diferentes a lo largo del proceso de emergencia y consolidación del presidencialismo mexicano), los tres subconjuntos del corpus (o complejo de corpora) mostraban realizaciones discursivas altamente diferenciadas con respecto a variables conscitutivas ("la forma de la lengua del discurso") en ese espacio institucional a lo largo del ciempo.

Por ejemplo, en el proceso de 1920 , la responsabilidad de iniciativa legislativa correspondió a un grupo de diputados de orientación ideológica 'radical' o progresista dencro de la Cámara, quienes a su vez ofrecían resisrencia a una iniciativa presidencial que todos ellos sabían dilecta (la creación de la actual Secretaría de Educación Pública), en condiciones de micro-coyuntura histórico-política sumamente enredadas, que el análisis tuvo que desenmarañar aunque no puedo exponer aquí (Carbó, 1996). 
Ése fue el caso de 1920, en tanto que transcurridos quince ańos, en 1935 , asistimos a un despliegue casi excesivo de c/reciente autoridad y poder presidencial: la Iniciativa de ley proviene del presidente general (revolucionario) Lázaro Cárdenas del Río, a la sazón dedicado a instituir y consolidar el luego famoso presidencialismo mexicano. En efecto, el presidence Cárdenas promovió con mano vigorosa la construcción del territorio institucional para el (unipersonal) ejercicio simbólico y operativo de más alto poder en el régimen; lo que en años posteriores, en el habla de funcionarios y allegados, serla reverencialmente aludido como: "las oficinas de (la) Presidencia" (y anexos y derivados). En 1935 y pocos meses antes del trámite legislativo analizado, habían sido desaforados un número elevado de legisladores de ambas Cámaras, presuntos o declarados partidarios del opositor al Presidente, el 'Jefe Máximo', el norteño general (revolucionario también) Plutarco Elías Calles. El Poder Legislativo se alineaba y auto-purgaba. En el funcionamiento parlamentario para la creación del Departamento de Asuntos Indígenas, la coyuntura reciente se tradujo en la ausencia completa de debate en el momento asignado a esta tarea legislativa. A la hora de la votación, hubo una sólida unanimidad, favorable desde luego (en versión idéntica a la presentada, faltaba más), a la creación de un departamento administrativo cuya obra institucional serla impresionante, y alcanzaría mítica condición fundacional en la estirpe de instituciones indigenistas mexicanas post-revolucionarias.

En 1948, por su parte, la escena se exhibe estabilizada en una forma canónica' para el ciclo de mayor éxito del modelo: una Cámara de Dipurados con oposición (casi sólo ritual pero presente y audible; vocinglera, de hecho) que recibe y aprueba, por amplísima mayoría de votos (ya no más monolírica unanimidad), iniciativas presidenciales en las cuales no ha introducido ninguna modificación de importancia, aunque ello se ha logrado, $y$ allí reside su importancia, sólo después de transcurrir un debate extenso y por momentos hasta acalorado entre los ciudadanos representantes parlamentarios (de diferences partidos, por añadidura).

Siento que nos encontramos, si se me permite una digresión, en un punto de riesgo con respecro a la verosimilitud de la legitimidad metodológica de la demostración teórica que sostengo haber alcanzado por medio del estudio empírico de caso que les estoy presentando (perdón por las asonancias récnicas). En concreto: me ha sido acribuida con desgraciada frecuencia "una gran suerte en el hallazgo" (stc) de materiales como los del corpus cuya construcción teórica me empecino en argumentar. Aprovecho la ocasión (como lo hago siempre, por lo demás) para formular una negativa rotunda: no exisce en este asunto más azar afortunado que el de la plausibilidad de la teoría de discurso con la cual trabajo, y de su aplicación metódica y sistemática, amén de explícita y regular, en un caso parricular y complejo.

La justeza de los materiales que el propio estudio construye como su objero de análisis está en deuda, sí, con la generosidad del acervo que se acumu- 
ló por medio de criterios léxicos, aplicados, como se dijo, de manera (manual y humanamente) estricta, aunque ello por sí sólo campoco es suficiente. Debe más bien su precisión o puntería ("tino" se diría en espahol mexicano contemporáneo) al tejido estrecho que existe entre lo que he llamado el saber histórico (el saber formularse preguntas históricas pertinentes o no triviales) y el desarrollo de la capacidad de escrutinio o de escucha, lectura, observación, análisis, descripción (lingüística inclusive), interpretación o como quiera llamársele, en el polo de las habilidades analfícas; esto es, la educación y formación del propio analista como instrumento y conductor del análisis (en el doble sentido de "transmisor eléctrico" y "guía"), gracias a su contacto cercano y prolongado con numerosos producros discursivos de una misma institución a lo largo de un ciclo histórico excenso; leídos y releídos y vueltos a releer (con esmerada $y$ distrafda atención).

\section{[y la lectura.]}

Ello se inscribe en lo que he llamado un uso teórico y metodológico de la lectura, y no hubiera sido tampoco suficiente si el análisis no se hubiera obligado además a transcurrir sobre una red de decisiones metódicas que se aplican de manera uniforme al conjunto de los materiales en sus respectivos niveles, $y$ de este modo funcionan como imprescindibles controles (científicos, podria decirse) en este asunto, quizás un poco inquietante, de la lectura como método (Carbó, 2001, 1996; véase sin duda Jitrik, 1982 y 1987). Resumiendo, diré que el análisis de discurso que inrenco practicar (de inspiración materialista y orientación semiótica sobre bases lingüisticas formales) se impone a sí mismo la rarea de hallar soluciones a problemas que podrían considerarse propios de la linguística descriptiva, en cuyo seno, como he dicho, este experimento anhela ser reconocido. Todo esto, desde luego, invoca interesantes discusiones sobre temas de reoría (del conocer), $y$ en torno al principio de evidencia o inclusive de compre/he/nsión que sería bonito desarrollar alguna día.

Por ejemplo, el asunto de la segmentación es un verídico asunto. En concreto, precisa una noción de froncera, simple y llana, entre unidades analíticas, con la complejidad conceptual y práctica que conlleva el establecimiento de tal principio sobre la (terca) evidencia empírica. No obstante, estoy convencida que los criterios para lo que se llama corte o parsing en análisis de discurso han de ser regulares y explícitos en los múltiples niveles de su objeto de análisis; en este caso, una constelación de complejos significantes como es el discurso. ¡Menudo problema! pues si movemos el punto de vista y el objeto observado, según diferentes colocaciones recíprocas, ese desplazamiento da como resulcado la ocurrencia de diferences perspectivas, ángulos y cortes posibles de segmencación (no arbitraria). 
Lamento no poder proseguir este tema, aunque sí debo decir que mi inspiración y gura aquil es la concepción memorable del maestro Benveniste (1976) sobre el nivel como un operador del propio análisis, y no como algo externo o impuesto al material. El concepto de nivel, junto con el principio de función, y he aqui una estructura que trabaja, pues las unidades del análisis lingülstico, dice Benveniste, sólo pueden ser establecidas como tales si constituyen partes funcionales del siguiente nivel. En el territorio crazado por estos principios cabe muy bien la noción de discurso con la que trabajo: un objeto de materialización en principio verbal, linguístico se diría. Pero además, y dada la capacidad generativa que lo discursivo tiene sobre los espacios sociales de concepción, desarrollo y combare de significaciones estratégicas (desde luego, no idénticas ni compartidas), el discurso como aparato semiórico es asimismo tributario del sistema de la lengua en su sentido más abstracto y poderoso: una estructura de partes finamente ajustadas, jerárquica, compleja y replicable sobre sí misma en una serie de ampliaciones y desplazamientos sucesivos; de hecho, potencialmente infinita o incesante, podría también decirse.

Aprovecho para subrayar que la práctica de segmentación, de re/des/construcción del material en series de datos, excluye ciertamente el uso ejemplarizador de fragmentos o trozos textuales de estatuto reórico y metodológico indefinido, provenientes de una edición discrecional normalmente no explícita; uso ilustrador de conceptos o argumentos, que se observa con cierta frecuencia en prácticas analíticas autodefinidas como análisis de discurso; dicho sea esto en disposición sólo didáctica, ruego que se me crea.

Otras decisiones hacia abajo, en niveles crecientemente 'micro', se van tejiendo con las ya expuestas: el material analizado en fino en lo verbal, que no es la cotalidad del corpus, y ello según criterios de pertinencia que no puedo detallar aqui aunque revisten gran importancia (Carbó, 1996) sigue siendo trabajado una y otra vez. Todo esto incide sobre la concepción y manejo de los datos y, en ese mismo territorio, sobre el asunto de los niveles y las unidades de análisis. Éstas pueden corresponder a textos completos, propios de diferentes etapas (fácticas o normativas) en una secuencia intertextual, o bien a párrafos, oraciones, sintagmas, lexemas o morfemas, si es preciso.

De regreso hacia arriba, esta estructura significante que trabaja puede llevarnos, con una mínima flexión verbal de pretérito (Carbó, 1996), desde la disonancia detectada por el oído analítico en la ocurrencia en una cierta zona textual, de una única forma verbal de pasado en l ra persona del plural, dentro de una serie extendida de formas de futuro simple en impersonal, hasta niveles superiores y superiores, de complejidad significante creciente, en una espiral semiótica que va desplegándose $y$, en cierto modo, señalando al moverse algunos lugares dónde indagar. Al mismo tiempo que se arienden esos enigmas en una suerte de estructurada entrega o 'rendición teórica' a su carácrer intrigante, la comprensión se amplía y se matiza. Por ejemplo, en el 
caso que he cirado arriba, la flexión de pretérito nos condujo hasta la detección de un pacto (extra y preparlamentario) entre sectores de la Cámara de Diputados; esto es, el espacio 'extralinguístico' de las cambiantes alianzas partidarias dentro del Poder Legislativo en el primer ciclo postrrevolucionario, y hacia los personajes más destacados de la escena política nacional con respecto a Poder Ejecutivo y más allá, en un momento dado entre junio de $1920 \mathrm{y}$ agosto de 1921 (Carbó, 1996).

\section{[Bueno, pero ¿cómo se hace ( $y$ d/escribe!) de manera acadé- micamente aceptable/realizable un simple proyecto de aná- lisis de discurso?]}

(Pienso que podría preguntar/se/me algún joven practicante de la disciplina.) Una empresa compleja de comprensión histórica y descripción verbal, según la persigue y desea cierto tipo de análisis de discurso, por ejemplo el 'materialista-semiótico-lingüístico' que practico y he intentado exponer, u otros afines, sólo pueden realizarse con muchos esfuerzos, hartas dificultades y una persistente curiosidad por el lenguaje, sumado codo ello a una docilidad extrema ante las exigencias, no sólo metodológicas, que demanda la delicada y exacta descripción de los fenómenos lingüísticos (Benveniste. 1976) ${ }^{3}$. Además, habré de señalar que, en mi caso y en otros que conozco cercanamente en México, algunos estudios (integrales) de discurso comaton mucho tiempo, en un contexto pre-post-moderno y pre-liberal-salvaje en la investigación institucional (Coronado, 1999; Fonte, 1998; Lema, 1998; Ruiz Ávila, 1998), obras mayores rodas que no sé si alcanzarían a madurar en los tiempos apremurados de las investigaciones de doctorados por proyecto que se imponen hoy en día. En cuanto a la marcha saludable de un proyecto análisis de discurso, en términos concretos, sólo puedo aconsejar, eso sí con énfasis, un trabajo ordenado $y$ generoso en cuanto al acervo, seguido por una labor despiadada de ceñimiento y ajuste del corpus de análisis, a fin de que ésce guarde una relación con las hipótesis del escudio que sea al mismo tiempo fina (o precisa) y flexible (o promisoria), además de económica y elocuente. (Sobre asuntos de la conscrucción del corpus, en un rexto más o menos complemenrario a éste, puede consultarse Carbó, en prensa; también Verón, 1971 en la p. $145, y$ alli mismo, $\left.n^{\circ} 9\right)$.

A lo largo y a lo ancho de este tejido metódico, los tiempos del análisis y de esta exposición se mueven y se traicionan ineludiblemence. Hay siempre en juego por parte del analista una suerte de '(más) saber', un saber que por principio se instituye (¿finge?) como ignorante: el 'no saber', y que de esa manera, distraída o absorta por principio, aguza la escucha, sensibiliza un esrado de sintonia $y$ alerta ante la lengua y sus figuras. En suma: intento asir lo 
que es, quizás ineludiblemente, una ficción metódica, en cuyo cranscurso las preguntas y las respuestas se van tejiendo de manera imperceptible aunque tenaz, según una dinámica cuya lógica profunda se revela siempre ex post. La figura de una luz oblicua conviene a lo que intento decir.

Luego entonces, es verdadero aunque también esencialmenre falso que sea sólo y en sí mismo un determinado uso verbal (la mentada flexión de pretérito, por ejemplo) el que, como un diamante con su propia luz, nos haya alertado sobre la evidente y altísima complejidad histórico-política en la cual transcurre la creación del Departamento de Educación y Cultura para la Raza Indígena (Decri) en 1920, y los movimientos posibles de los participantes en esa escena dada. Es cómico, por su parte, pensar que algo en lo histórico (en cuanto historiográfico) podía habernos sugerido observar en particular el paradigma de tiempos verbales en ese texto específicamente (que es a su vez una parte de un turno de habla en el conjunto de 58 rurnos transcurridos en el debate). Aunque, desde luego, es también verdadero que el turno en el que el fenómeno ocurre en la sesión es uno de los que categorizo "turnos discursivos mayores" (Carb6, 1996), en boca de un personaje (acror, participante, figura) que ocupa un punto específico de intersección de líneas de adscripción (o suma de rasgos caracrerísticos), y que historiográficamente se perfila esencial en la micro/coyuntura. Toda esta información proviene de diferentes 'paradas', close-ups (en el sencido visual o perceprivo global), o puntos de observación, que son derectados, construidos a lo largo de una apreciación global de, en este caso, la fuerza pragmática que se implica en ese "episodio interaccional" dencro de la estrucrura de la sesión como un todo (Carbó, 1996).

Confío que se perciba ya un poco más desarrollada la noción de una lectura de orden linguístico que, además de no ser sorda, procura no ser mensa (coloquialismo mexicano por "tonta", "ingenua"; fig. "plana"), pues ha sido sisremáticamence desencantada, iluminada, por un cierto saber histórico. De todos modos es, insisto, lectura, y es también linguística, tanto en sentido estricto como lato. Quisiera a este respecro invocar, como lo hago con frecuencia, la noción de 'delicadeza analítica', y anriciparme a las críticas (frecuentes también) sobre su cómoda imprecisión. Empleo esta noción para referirme no sólo a un nivel de detalle o profundidad en el análisis, sino también (o quizás sobre todo) a una disposición (isentimental?) hacia la naturaleza e inrensidad del movimiento que acerca, vincula, al analista a su objeto. Mi uso se inspira en lo que Jakobson (1981) ha llamado awareness: un estado de alerta, un tipo de atención en el que se combina la percepción de las múltiples funciones de un texto con la aprehensión de su incegridad. Asirnismo, el analista de discurso podría ser concebido como Benveniste definiera al psicoanalista: alguien que escucha "los desgarrones del discurso" (1976). Se comprenderá, sin duda, el valor insustituible de la preservación de la literalidad en un acercamiento de esta índole a los procesos y productos discursivos. 


\section{¿Cómo concluir?}

No lo sé, por lo que aprovecharé para añadir que, a la antigua usanza en la linguística, dos dimensiones básicas en mi práctica de análisis son forma y lugar de ocurrencia de los fenómenos que se analizan. El concepto de forma ha sido suficientemente argumentado. El de lugar, por su parte, da cabida al tiempo, no sólo el tiempo histórico de los grandes relaros o mitos (o formas de periodización histórica) para un cierto caso, sino también el tiempo del análisis, en sus diferentes decursos según los distintos niveles del objeto, allí incluida también la materialización verbal con la que lo temporalizado (lo que ya ocurrió) se va encarnando en el desarrollo de los propios textos y procesos. Locación final es un área textual tan subrayada o densa como locación inicial, a la que Barthes (1987, en la pág. 166, nota 13) llamó el lugar de la lucha contra la afasia.

Concluiré entonces subrayando que el escablecimiento de niveles y unidades en el material que integra el corpus, y su consecuente re/integración (shuffling and reshuffling expresa mejor mi idea, con permiso), al igual que numerosos movimientos metódicos asociados en series de aplicación paralela o secuencial, y que no he podido desarrollar ahora, sustentan un proceso de análisis que reconoce su filiación en ciertos principios básicos de la lingüística estructural clásica. En esa misma fuente, leída y releída durante años, en esos maestros admirables, encuentro inspiración para un acercamiento al lenguaje que, como reza el título de este trabajo, no desdeña tocarlo con la mano. Se funda en una concepción a la vez materialista y abstracta del funcionamiento de los procesos significantes, que no reconoce fronteras de tipo sustancial entre lo que se acepta como lingüisrico (o verbal) y lo que se señala diferente de lo lingüístico; lo extralinguístico, a menudo bajo la designación de contexto (otra discusión que no haré hoy).

Así, la observación y tratamiento del asunto en forma a la vez paradigmática y sintagmática puede ampliarse, tal como lo señalara en 1970 Roman jakobson (1976), en un crecimienro de sucesivos dominios analíticos. Tales dominios o regímenes han de estar dotados de capacidad para movimientos oblicuos y recursivos sobre la estructura complera del objero re/des/construido, me atrevo a añadir, aunque es seguro que esto se implicaba en la observación del maestro. El único límite a este inagotable des/re/tejido de redes habría de ser, lo admito, el del delirio cocal o, preferiblemente, el de las lindes razonables que ha de fijarse a si misma una empresa de estudio decidida, a pesar de todo, a mantenerse en el reino de este mundo.

Quisiera añadir que, dada la naturaleza de su objeto de estudio (discurso de tipo parlamentario), es crucial en mi trabajo el análisis específico diseñado para el tratamiento de una situación interaccional como la que le concierne, de tipo institucional, público, oral, momencáneo, múltiple y cara a cara (debare en sesión parlamentaria). Para ello acudo al aparato formal del análisis conversacional, tal como fuera formulado con ejemplar claridad por Sacks 
y otros (1974), y lo hago con auténtico placer intelectual. Claro está que me esfuerzo en enriquecerlo con la inserción (estructurada) del ya mencionado saber histórico, tal como se proyecta sucesiva o simultáneamente sobre los mismos conjuntos de hablantes, en la forma de pares de rasgos contrastados (Carbó, 1992).

Diré en breve que el escrutinio de la dimensión pragmática de los desempeños interaccionales de los participantes en el nivel local, se inserta en una amplia estructura analítica, en una lectura compleja y extensa del caso, que es la que he intentado presentar. En materia interaccional, entonces, el valor polémico de un turno de habla en una cierta locación, la ocurrencia o no de interrupciones a lo largo de una intervención, o la forma dada a un tramo textual de apertura de turno (en contra del asunto a debate, por ejemplo), se construyen como datos de manera semejante a la flexión verbal de pretérito: hilos que se van ligando en el laberinto del sentido del decir, a partir de una observación/escucha de su forma/lugar específicos (Carbó, 1996).

De hecho, todo el análisis de la construcción verbal que los actores participantes hacen de sí mismos, y en conjunto, el establecimiento de una suerte de mapa o red entre los mismos, descansa sobre el mismo doble movimiento de saber/no saber, paradigma/sintagma, forma/lugar, pregunta/respuesta, 'micro'/macro', historia/lengua, que impulsa la empresa toda.

Compartiendo, como lo hago, la admiración enamorada que tan grandes maestros han dedicado al fenómeno de la lengua, y a la estructura exquisita de su poder significante, mi meta es emular su informado y riguroso asombro. ¿Qué otra cosa, si no, es el análisis?

NOTAS

1. Nota para lectores no argentinos: llegué a México, en efecro, en ese mismo año, como tantos otros cordobeses de la Úniversidad Nacional. Habiamos sido parte (afortunada según lo que vino después) de la limpieza ideológica y polírica que, en algunas provincias (Córdoba, notoriamente), precedió a la dictadura milicar. Ésta se instauró en marzo de 1976, por medio de un golpe de estado contra la hasta entonces Presidenta de la República, señora lsabel Marrínez, viuda de Perón.

2. Nota para lectores argentinos y no argentinos: me honra descacar que, provenientes no sólo de la Faculıad de Filosofía y Humanidades de la Universidad Nacional de Córdoba, sino inclusive de la misma Escuela de Letras Modernas que fue la mía, han hecho presencia insusticuible en la investigación y la crírica en México, los siguientes queridos colegas: Horacio Crespo (1988-90), Raúl Dorra (1981, 1989, 1994), Antonio Marimón (que en paz descanse; 1999a y b), Mabel Piccini (ed., 1989, 2000), Mier y Piccini (coord., 1987), Luisa Ruiz Moreno $(1993,1998)$ y Carlos Zolla $(1984,1988)$. Sin olvidar, por supuesto, a Noé Jitrik (1982, 1985, 1987, 1988; ed. 1990, 1991, 1993), fundador de la revisca Discurso y baluarte de la misma durante ahos en la UNAM. No coincidí con él en Córdoba pues se exiló en Francia cuando el gol- 
pe del General Juan Carlos Onganía en 1966. Después, en México. me dio clases en el doctorado del Cell (Centro de Estudios Lingúísticos y Literarios, El Colegio de México), en 1978.

3. Como de coscumbre, el maestro merece ser escuchado en su propia voz. En el prefacio al primer volumen de los Problemas, dice: "Quienes descubran en otros dominios la imporrancia del lenguaje, verán asi [fórico; por los trabajos alls incluidos] cómo aborda un lingüisra algunas de las cuestiones que se [le] plantean, $y$ acaso adverrirán que la configuración del lenguaje decermina codos los sistemas semióticos. A aquéllos habrá páginas que les podrán parecer difíciles. Que se convenzan de que el lenguaje es por cierro un objeto dificil, $y$ de que el análisis del dato lingǘfstico se consuma por vass arduas".

4. Estos temas se acercan a una (necesaria) reflexión sobre los procesos formarivos de la superficie textual, o morfología (lingüística, significante) de los fenómenos discursivos. En ese complejísimo territorio, está implicado, entre tantos otros, el rema de la 'huella' en análisis de discurso; asunto de mucho interés que rampoco podré desarrollar en esta ocasión, aunque concierne a un autor que leo con provecho, el ya cirado Eliseo Vetón. Diré sólo que, aunque la noción de huella se reje más o menos fluidamence con su exposición del concepto de semiosis infinita, estoy convencida de que tal designación es una mala decisión léxica. Pienso que una concepción materialista de los procesos sociales, alli incluidos los de construeción de sentido; esco es, una visión globalmente semiórica de lo significante, excluye el principio de huella como evidencia del tránsito de un fenómeno de sentido desde un nivel a otro (más o menos discretos ambos) y, sobre todo, excluye la presuposición de que la huella sería un 'rastro', un fragmento de evidencia de una matcrialidad significante regida por diferentes principios de los de su origen. Por lo demás, su obra (alguna de la cual incluyo en esra bibliografía), además de coetánca a la de Michel Pecheux y oblicua de muy inreligente manera con respecto a la hegemonía de ésca, fue seminal en la conscitución del campo del discurso. Pecheux, a su vez, acusó serio recibo de las observaciones que en ese viempo le formularon Verón $y$ Fisher (Pecheux, 1978).

\section{REFERENCIAS BIBLIOGRAFICAS}

Aguilar Camin, H. y Meyer, L. (1989). A La sombra de la Revolución Mexicana. México: Cal y Arena.

BARTHES, R. (1983). El grano de la voz. México: Siglo XXI.

BARTHES, R. (1986). Fragmentos de un discurso amoroso. México: Siglo XXI.

BarTHES, R. (1987). El susurro del lenguaje. México: Paidós Comunicación.

BenVeniste, E. (1976). Problemas de linguiistica general l. México: Siglo XXI.

BenvenISTE, E. (1977). Problemas de lingüissica general II. México: Siglo XXI.

BRADBY, B. (1989). Review of Teresa Carbó y otros, Una lecrura det sismo en la prensa capitalina, Cuadernos de la Casa Chara, Ciesas, México, 1987. Sociolinguistics, 18, 116-18.

Calvino, I. (1990). Las ciudades invisible. México: Minotauro.

CARBO, T. (1984). Discurso politico: Lectura y análisis. México: Cuadernos de la Casa Chata 105, Ciesas.

Carbo, T. (1987). ¿Cómo habla el Poder Legislarivo en México? Revista Mexicana de Sociologia, 43, (2), 165-180.

CARBO, T. (1992). Determinaciones discursivas sobre episodios interaccionales en situación de debate parlamentario. Morphé, 8, 25-51. 
CARBO, T. (1996). El discurso parlamentario mexicano entre 1920 y 1950 (Un estudio de caso en metodologia de análisis de discurso). Vols.1-2. México: Ciesas y El Colegio de México.

CARBO, T. (1997). Sobre por qué hacer un estudio de discurso parlamentario en un régimen presidencialista. En Krotz, E. (coord.). La cultura politica mexicana: Perspectivas para su estudio. pp. 215-251. México: Consejo Nacional de la Cultuta y las Artes (CNCA) y Ciesas.

CARBO, T. (2001). Regarding reading: On a methodological approach. Discourse or Society, 12, (1), 59-89.

Carbo, T. (2001). El cuerpo herido o la constitución del corpus en análisis de discurso, Escritos, 20-21, (julio-diciembre), 19 pp. México: Centro de Ciencias del Lenguaje de la Universidad de Puebla.

Carbo, T. Franco,V., Torre, R, De la y Coronado, G. (1987). Una lectura del sismo en la prensa capitalina. México: Cuadernos de la Casa Chata 147. Ciesas.

Coronado, G. (1999). 'Porque hablar dos idiomas es como saber más ..' Sistemas comunicativos bilingues ante el México plural. México: Ciesas y Conacyt.

Crespo, H. (1990). Historia del azúcar en México. Vols. I-3. México: Fondo de Cultura Económica.

DORRA, R. (1981). Los extremos del lenguaje en la poesta tradicional española. MéxiCo:UNAM.

Dorra, R. (1989). Hablar de literatura. México: Fondo de Cultura Económica.

Dorra, R. (1994). Profeta sin honra. México: Siglo XX] y Benemérita Universidad de Puebla.

Elchenbaum, B. (1970). La ceorfa del 'mérodo formal'. En Todorov, T. (comp.). Teoria de la literatura de los formalistas rusos. pp. 21-54. Buenos Aires: Signos.

FONTE, I. (1998). Cuba 1906-1921: Versiones de ha nación en el discurso periodistico. Tesis doccoral. México: El Colegio de México.

GARZA, R. DE LA (1972). The Mexican Chamber of Deputies and the Mexican Political System. PhD. Tesis. Arizona: Universidad de Arizona.

JAKOBSON, R. (1976). Nuevos ensayos de lingüística general. México: Siglo XXI.

JAKOBSON, R. (1981). Selected Writings. Vol. III: The poetry of grammar and the grammar of poetry. New York: Mouron Publishers.

JITRIK, N. (1982). La lectura como actividad. México: Premia Edicora.

JiTRIK, N. (1985). El melódico perplejo. México: Universidad Autónoma Mctropolirana-Izrapalapa, Serie Correo Menor.

Jitrik, N. (1987). Lectura y cultura. México: Biblioteca del Edicor, Coordinación de Humanidades, UNAM.

JiTflk, N. (1988). El balcón barroco. México: UNAM.

JiTRIK, N. (1990). El dominio y la palabra (Los discursos sociales). Vol. I Serie Discurso y Sociedad. México: UNAM.

JTRIK, N. (1991). Irrupción del discurso (Discurso e interdisciplina). Vol 2 Serie Discurso y Sociedad. México: UNAM.

JITRIK, N. (1993). Las variables y el continuo (El discurso politico en Mexico). Vol. 3 Serie Discurso y Sociedad. México: UNAM.

KrauzF, E. (1997). La presidencia imperial ascenso y caida del sistema politico mexicano (1940-1996). México: Tusquets.

Lema, R. (1998). Los dialogos del Calepino de Motul: Exploraciones en la historiografia de la otredad. Tesis doctoral. México: UNAM.

LustıG, N. (1992). Mexico: The Remaking of an Economy. Washingron: Brookings Institution. 
Maldidier, D. (1971). Discours politique de la guerre d'Algéric. Langages, 23 (Le discours politigue), 57-86.

MARIMON, A. (1999). Mis voces cantando. México: Era.

Marimón, A. (1999). Ultimo tango en Buenos Airex, Diego (Poetas, puigiles, futbolistas y mitos). México: Cal y Arena.

Meyer, L. (1976). El primer tramo del camino. En Historia General de Mexico, vol. 4. pp. 111-199, México: El Colegio de México.

Meyer, L. (1976). La encrucijada. En Historia General de México, vol, 4, pp. 201 283, México: El Colegio de México.

Meyer, L. (1977). Historical roors of the authoritarian state in México. En Reyna, J. L. $y$ Weinert, R. S. (eds.). Authoritarianism in Mexico. pp. 3-22. Filadelfia: Insticute for the Srudy of Human Issues.

MIER, R. Y PiCCINI, M. (1987). El desierto de espejos (Juventud y television en México). México: Universidad Autónoma Metropolitana y Plaza \& Valdés.

PICCINI, M. (1989). La imagen del tejedor (Lenguajes y poltticas de La comunicación). México: Felafacs y Gustavo Gili.

Piccini, M. Y OTRos (2000). Recepción artistica y consumo cultural. México: Consejo Nacional para la Culcura y las Artes y Ediciones Casa Juan Pablos.

Ruiz AvILA, D. (1998). Tejiendo discursos se tejen sombreros. Identidad y práctica discursiva. Tesis docroral. México: ENAH.

Ruiz Moreno, L. y Tonantzintla, S. M. (1993). El relato en imagen. México: Consejo Nacional para la Cultura y las Artes.

Ruiz Moreno, L. (1998). Las más bellas biblias. México: Benemérita Universidad de Puebla y Gobierno del Esrado de Puebla.

SACKS, H., SCHEGLOFF, E. A. Y JefERSON, G. (1974). A simplest sysrematics for the organizarion of rurn-ralking for conversation. Language. 50,696-735.

VERÓN, E. \{1971). Ideología y comunicación de las masas: Ja scmanización de la violencia política. En Verón, E. y otros (eds.). Lenguaje y comunicación social. 133-191. Buenos Aires: Nueva Visión.

Verón, E. (1980). La semiosis social. En Toledo, M. (ed.). El discurso politico. 145. 165. México: Nueva Imagen y UNAM.

Veron, E. (1987). Construir el acontecimiento. Buenos Aires: Gedisa.

VERON, E. (1992). La semiosis social (Fragmentos de una teorta de la discursividad). Buenos Aires: Gedisa.

VERón, E. (1995). Semiosis de lo ideológico y del poder. Buenos Aires: Secretaria de Excensión Universitaria, Facultad de Filosofía y Letras, UBA.

VERON, E. Y FISHER, S. (1973). Baranne est une creme. Communications, 20, 162-181.

VERON, E. Y OTROS. (1987). El discurso politico. Lengrajes y acontectmientos. Buenos Aires: Hachette.

ZOLLA, C. Y LOZOYA, X. (1984). La medicina invisible (Introduccion al estudio de la medicina tradicional de Mexico). México: Folios.

Zolla, C. Y OTROS. (1988). Medicina tradicional y enfermedad. México: Centro Inreramericano de Estudios de Seguridad Social. 
TERESA CARBO es lingüista, investigadora ritular del Ciesss (Centro de Estudios Avanzados en Antropología Social) en Ciudad de México. Ha (rabajado en discurso político, parlamentario y de los medios. Desde hace algún tiempo le preocupan cues. riones teóricas relacionadas con el mérodo. En este momento está empezando a investigar sobre las práccicas comunicativas entre nares sobre los prococolos para construir dacos, en grupos virtuaies de investigación especiàizada, cales como análisis del discurso. Es una de las fundadoras de la ALED (Asociación Latinoamericana de Escudios del Discurso) y co-edirora de la revicra Discourse and Soczery. Correo elecrónico: tcarbo@juarez,ciesas.edu.mx 